\title{
Research on the Relationship Between Self-Management Efficacy and Quality of Life for Breast Cancer Patients Receiving Endocrine Therapy
}

\author{
Hongjie Yi \\ The First Affiliated Hospital of China Medical University \\ Haoran Jiang \\ The First Affiliated Hospital of China Medical University \\ Aiping Wang \\ The First Affiliated Hospital of China Medical University \\ Wei Zong \\ The First Affiliated Hospital of China Medical University \\ Yu Dong \\ The First Affiliated Hospital of China Medical University \\ Yao Li ( $\square$ Irene950117@163.com ) \\ The First Affiliated Hospital of China Medical University
}

\section{Research Article}

Keywords: Breast cancer, Self-management, Self-efficacy, Quality of life

Posted Date: January 3rd, 2022

DOI: https://doi.org/10.21203/rs.3.rs-1126991/v1

License: (c) (i) This work is licensed under a Creative Commons Attribution 4.0 International License. Read Full License 


\section{Abstract \\ Purpose}

To investigate the status quo and relationship between self-management efficacy and quality of life (QOL) of patients with breast cancer undergoing endocrine therapy, and to explore the influencing factors of QOL.

\section{Methods}

The convenience sampling method was used to select 240 patients who received endocrine therapy after breast cancer surgery in the First Hospital of China Medical University, the self-designed general data questionnaire, selfmanagement efficacy questionnaire for breast cancer patients with endocrine therapy and quality of life scale for breast cancer patients were used to investigate. The frequency, percentage, mean \pm standard deviation were used to describe patients' self-management efficacy and quality of life. Pearson correlation analysis was used to analyze the relationship between self-management efficacy and quality of life, and univariate analysis and multiple stepwise regression were used to analyze the influencing factors of QOL.

\section{Results}

The scores of self-management efficacy and QOL of patients with breast cancer endocrine therapy were $125.21 \pm$ 25.57 and $153.33 \pm 19.31$ respectively, which were at the middle level; self-management efficacy was significantly positively correlated with quality of life $(p<0.01)$; multiple stepwise regression results showed that selfmanagement efficacy, the number of physical symptoms, monthly family income and recurrence and metastasis were the influencing factors of QOL.

\section{Conclusion}

The self-management efficacy of endocrine therapy was positively correlated with QOL in breast cancer patients. The higher the self-management efficacy of endocrine therapy, the better QOL in breast cancer patients. Selfmanagement efficacy is the main factor affecting the quality of life of breast cancer patients undergoing endocrine therapy. Improving the level of self-management efficacy can improve their quality of life.

\section{Introduction}

Breast Cancer (BC) is the most common malignant tumor in women worldwide [1] and also causes the largest number of deaths among women worldwide [2]. The latest global cancer burden data released by THE World Health Organization/International Agency for Research on Cancer (WHO/IARC) in December 2020 [3] showed that the number of new cases of breast cancer in 2020 was as high as 2.26 million (11.7\% of the newly diagnosed cancer), and the number of deaths was more than 680,000 (6.9\%). In China, the number of new cases of breast cancer reached 426,000 , with 117,000 deaths. The incidence and mortality rate of breast cancer are still rising[3,4].

Endocrine therapy for breast cancer mainly reduces or clears estrogen levels in the body through some drugs or treatments, thereby inhibiting the growth of breast cancer and reducing the risk of recurrence and metastasis [5, 6], which plays an important role in the comprehensive treatment of breast cancer [7]. Studies [8-12] show that most 
patients with endocrine therapy for breast cancer have experienced hot flashes, night sweats, insomnia, joint stiffness, weight gain, anxiety, depression and other symptoms, and the long treatment cycle will make patients become depressed and indifferent. Therefore, in the process of treatment and rehabilitation of patients with breast cancer endocrine therapy, it is particularly important for patients to actively participate in the management of the disease and establish an effective self-management model. Self-efficacy is a core concept in self-management theory, and studies have confirmed that the self-management behavior of breast cancer patients is affected by selfefficacy, and the higher the level of self-efficacy, the better the self-management behavior [13]. Based on the endocrine therapy of breast cancer patients quality of life of the related research is less involved in self-management efficacy problems, this study aims to investigate the status quo of self-management efficacy and quality of life of breast cancer patients undergoing endocrine therapy, clarify the relationship between self-management efficacy and QOL, and provide reference for the formulation of nursing intervention programs to improve patients' selfmanagement efficacy and improve patients' QOL.

\section{Methods}

\section{Participants}

From May 2016 to September 2016, convenience sampling method was used to select patients who received endocrine therapy after breast cancer surgery in the Department of Breast Surgery of the First Affiliated Hospital of China Medical University as the research subjects. Inclusion criteria: pathological diagnosis of breast cancer and postoperative endocrine therapy for more than 1 month; above 18 years old; complete cognitive and behavioral abilities; patients were willing to participate in the study with informed consent. Exclusion criteria: combined with more serious cognitive and mental disorders; combined with complicated diseases that seriously affect the quality of life.

\section{Sample size}

In multi-factor analysis, 10 times of the independent variable is considered appropriate. There were 20 independent variables in this study, and $20 \%$ invalid questionnaires should be considered. The final sample size was 240 cases. Invalid questionnaire criteria: more than $20 \%$ of the items in the whole questionnaire are not answered; the whole questionnaire was wavy or monosyllabic.

\section{Data collection and measurements}

\section{General Data Questionnaire}

It was designed by researchers themselves, including demographic data (age, height, weight, race, level of education, employment status, lifestyle, marital status, monthly family income, medical payment method, etc.) and disease related information questionnaire (postoperative time, start time of endocrine therapy, menstrual status, physical symptoms, complications, recurrence, metastasis, etc.).

\section{Self-management efficacy questionnaire for breast cancer patients undergoing endocrine therapy [14]}

The questionnaire consisted of 33 items from 4 dimensions, including 9 items of life/emotion, 7 items of disease coping, 9 items of society/family and 8 items of compliance behavior.Likert5-level scoring method was used in the questionnaire, ranging from "no confidence" to "very confidence", and the higher the score, the higher the level of selfmanagement efficacy. The Cronbach's a coefficients of the total questionnaire were 0.972 , and the Cronbach's a 
coefficients of the four dimensions ranged from 0.895 to 0.949 . The I-CVI of the questionnaire ranged from 0.80 to 1.00 and the S-CVI was 0.966 . The retest reliability was 0.913 .

\section{Quality of Life Instruments for Patients with Breast Cancer[QLICP-BR)[15,16]}

The scale developed by the Chinese scholars Chong-hua Wan, combined with China's economic and cultural background and value system, specially for measuring the breast cancer patient health related quality of life, a total of 39 items, consisted of the common module QLICP - GM and breast cancer specific entry form; using Likert 5 grade evaluation method, from "no" to "very" count 1-5 points, respectively. There are both positive and negative scoring items in the scale. The higher the score of the positive item, the better the quality of life; the higher the score of the negative item, the worse the quality of life. The Cronbach's a coefficient of internal consistency of social dimension was 0.58 , and the other dimensions were greater than 0.65 . The retest reliability of the scale was 0.88 . In addition, some studies have proved that the internal consistency Cronbach's a coefficient of this scale is $0.81[17]$.

\section{Survey methods}

Questionnaire was distributed by the researcher himself. Before the investigation, researcher explained the purpose and significance of the study to the patients, promised to keep their information strictly confidential, and the patients signed the informed consent form. In the process of filling in the questionnaire, patients' questions were answered in time. For those patients who were not convenient to fill in the questionnaire by themselves or had poor eyesight, the researcher read the questions for the patients one by one, and then the patients answered by themselves or the researcher recorded their answers. The questionnaire was filled in anonymously, and was taken back on the spot after filling in, and checked whether there was any missing content. If there was any missing or unclear content, the questionnaire was returned to the patient in time for checking and filling to ensure the integrity of the results.

\section{Statistical analysis}

SPSS 20.0 software was used for statistical analysis. Descriptive statistics included frequency, percentage, mean and standard difference, etc. and inferential statistics included T test, Pearson correlation analysis, one-way ANOVA and multiple step-up regression analysis, etc. $P<0.05$ was statistically significant.

\section{Results}

A total of 300 questionnaires were sent out and 240 were effectively received with effective recovery rate of $80 \%$. All subjects were female, aged between 30 and 78 years old, with an average age of $52.89 \pm 9.67$ years old.

\section{Status quo of self-management efficacy of patients undergoing endocrine therapy for breast cancer}

The average score of self-management efficacy of patients undergoing endocrine therapy for breast cancer was $125.21 \pm 25.57$, among which $48.3 \%$ of patients with total score higher than the average were in the middle level(Table 1).

Table 1 Scores of self-management efficacy and dimensions $(n=240)$ 


\begin{tabular}{llll} 
& Minimum & Maximum & Mean \pm SD \\
\hline Self-management efficacy & 57 & 165 & $125.21 \pm 25.57$ \\
\hline Life/emotion & 18 & 45 & $35.36 \pm 7.75$ \\
\hline Disease coping & 11 & 35 & $26.30 \pm 6.23$ \\
\hline Society/family & 11 & 45 & $32.26 \pm 7.74$ \\
\hline Compliance behavior & 15 & 40 & $31.28 \pm 6.53$
\end{tabular}

\section{Status quo of QOL of patients undergoing endocrine therapy for breast cancer}

The average score of QOL of breast cancer patients treated with endocrine therapy was $153.33 \pm 19.31$, and $54.2 \%$ of them were higher than the average score, which was generally in the middle level( Table 2).

Table 2 QOL and score of each dimension ( $n=240)$

\begin{tabular}{lllll} 
& Minimum & Maximum & Mean \pm SD & Standardized score \\
\hline QOL & 93 & 193 & $153.33 \pm 19.31$ & 73.29 \\
\hline Physical function & 15 & 35 & $27.90 \pm 4.07$ & 74.64 \\
\hline Mental function & 24 & 60 & $44.31 \pm 8.09$ & 67.33 \\
\hline Social function & 14 & 30 & $23.77 \pm 4.03$ & 74.05 \\
\hline Common symptoms and side effects & 7 & 35 & $28.96 \pm 5.64$ & 78.42 \\
\hline Specific modules & 9 & 35 & $28.38 \pm 4.65$ & 76.35
\end{tabular}

Correlation between self-management efficacy and quality of life in breast cancer patients undergoing endocrine therapy

The total score of self-management efficacy and all dimensions were significantly positively correlated with the total score of quality of life $(p<0.01)$, self-management efficacy was significantly positively correlated with physical function, physiological function, social function and breast cancer specific modules of quality of life $(p<0.01)($ Table 3).

Table 3 Correlation between self-management efficacy and QOL(n=240) 


\begin{tabular}{|c|c|c|c|c|c|}
\hline & $\begin{array}{l}\text { Self-management } \\
\text { efficacy }\end{array}$ & Life/emotion & $\begin{array}{l}\text { Disease } \\
\text { coping }\end{array}$ & Social/family & $\begin{array}{l}\text { Compliance } \\
\text { behavior }\end{array}$ \\
\hline QOL & $0.404^{\star \star}$ & $0.425^{\star \star}$ & $0.403^{\star *}$ & $0.303^{* *}$ & $0.320^{\star *}$ \\
\hline Physical function & $0.423^{\star *}$ & $0.452^{\star \star}$ & $0.436^{\star \star}$ & $0.329^{\star \star}$ & $0.336^{* *}$ \\
\hline Physiological function & $0.335^{\star *}$ & $0.341^{* *}$ & $0.323^{\star \star}$ & $0.256^{* *}$ & $0.270^{\star *}$ \\
\hline Social function & $0.317^{\star \star}$ & $0.317^{* \star}$ & $0.306^{\star *}$ & $0.245^{\star \star}$ & $0.266^{\star *}$ \\
\hline $\begin{array}{l}\text { Common Symptoms and } \\
\text { side effects }\end{array}$ & 0.040 & 0.087 & 0.072 & -0.014 & 0.010 \\
\hline Specific modules & $0.520^{* *}$ & $0.510^{* *}$ & $0.509^{* *}$ & $0.427^{* *}$ & $0.442^{* *}$ \\
\hline
\end{tabular}

Note: $* * p<0.01$

\section{Univariate analysis of quality of life patients treated with endocrine therapy of breast cancer}

According to the results of independent sample T test and one-way ANOVA, age, BMI, marital status, monthly family income, number of physical symptoms, fatigue, nausea, insomnia, recurrence and metastasis, and self-management efficacy had statistically significant effects on QOL $(p<0.05)$ (Table 4).

Table 4 One-way ANOVA of influencing factors of QOL $(n=240)$ 
Item

n QOL

Item

n QOL

$S$

Agelyear[

$\leq 39$

40ه49

$50 \rrbracket 59$

$60 \otimes 69$

$\geq 70$

BMI

$\leq 18.50$

$18.51 \rrbracket 24.99$

$25.00 \rrbracket 29.99$

$30.00 \otimes 34.99$

$35.00 \rrbracket 39.99$

Marital status

Married/cohabit $208 \quad 73.43 \pm 12.23$

Unmarried

7

Divorced

Separated

Widowed

Degree of education

Primary school $\quad 1 \quad 55.13 \pm 0.00$

or below

Unior high

school

High school/

technical

secondary

Junior college $\quad 56 \quad 74.75 \pm 12.54$

Bachelor's $\quad 34 \quad 76.23 \pm 11.92$

degree or above

Monthly family incomelyuan!

$107 \quad 70.79 \pm 12.89$
$F / t \quad P$

$2.942 \quad 0.021 \quad$ Endocrine therapy time (month)

$1 \otimes 12$

$10572.24 \pm 11.43$

$13 \llbracket 24 \quad 55 \quad 74.96 \pm 13.63$

$25 \llbracket 36 \quad 40 \quad 75.29 \pm 11.17$

$37 \rrbracket 48 \quad 25 \quad 73.59 \pm 13.61$

$49 \llbracket 60 \quad 7 \quad 64.93 \pm 14.45$

$\begin{array}{lll}2.883 & 0.023 \quad \varangle 60\end{array}$

Number of physical symptoms

4.17

0.003

$\begin{array}{lll}0 & 136 & 75.39 \pm 12.16\end{array}$

$\begin{array}{lll}1 & 66 & 72.13 \pm 10.71\end{array}$

$\begin{array}{lll}2 & 26 & 69.85 \pm 13.94\end{array}$

$\begin{array}{lll}3 & 9 & 65.60 \pm 15.01\end{array}$

$\begin{array}{lll}4.254 & 0.002 \quad 4\end{array}$

$3 \quad 55.98 \pm 8.01$

Ethnic

0.41

0.682

group

Han $221 \quad 73.38 \pm 12.26$

Minority $19 \quad 72.17 \pm 14.00$

Whether to live alone

$0.42 \quad 0.675$

$\begin{array}{lll}\text { Yes } & 27 & 72.34 \pm 11.57\end{array}$

$\begin{array}{lll}1.892 & 0.113 \quad \text { No }\end{array}$

$21373.41 \pm 12.50$

Whether to have any

occupation

$-1.34 \quad 0.181$

$\begin{array}{lll}\text { Yes } & 77 \quad 74.84 \pm 12.96\end{array}$

No $\quad 163 \quad 72.55 \pm 12.07$

Whether to have children

$0.368 \quad 0.713$

Yes $\quad 218 \quad 73.19 \pm 12.22$

$\begin{array}{lllll}2.555 & 0.040 & \text { No } & 22 & 74.21 \pm 14.16\end{array}$

Whether to have children in the $\quad \begin{array}{lll}-1.38 & 0.168\end{array}$ future

$\begin{array}{lll}\text { Yes } & 11 \quad 78.32 \pm 11.07\end{array}$ 


\begin{tabular}{|c|c|c|c|c|c|c|c|c|c|}
\hline $6001 \otimes 10000$ & 27 & $73.62 \pm 9.10$ & & & No & 229 & $73.04 \pm 12.41$ & & \\
\hline $10001 \otimes 12000$ & 3 & $80.13 \pm 14.43$ & & & \multicolumn{3}{|c|}{ Other diseases } & 1.365 & 0.173 \\
\hline$\geq 12000$ & 7 & $80.40 \pm 7.48$ & & & Yes & 76 & $71.69 \pm 10.69$ & & \\
\hline \multicolumn{3}{|c|}{ Medical payment method } & 1.184 & 0.308 & No & 164 & $74.03 \pm 13.05$ & & \\
\hline Public expense & 10 & $67.69 \pm 15.66$ & & & \multicolumn{5}{|c|}{ Physical symptom } \\
\hline $\begin{array}{l}\text { Medical } \\
\text { insurance }\end{array}$ & 220 & $73.44 \pm 12.25$ & & & fatigue & & & 3.211 & 0.002 \\
\hline \multirow[t]{2}{*}{ Self-pay } & 10 & $75.38 \pm 11.55$ & & & Yes & 67 & $69.24 \pm 12.82$ & & \\
\hline & & & & & No & 173 & $74.85 \pm 12.82$ & & \\
\hline Smoke & & & 0.014 & 0.986 & Nausea & & & 2.948 & 0.004 \\
\hline No smoking & 231 & $73.27 \pm 12.48$ & & & Yes & 9 & $61.54 \pm 15.90$ & & \\
\hline $\begin{array}{l}\text { Used to smoke } \\
\text { and quit } \\
\text { Smoking. }\end{array}$ & 8 & $73.80 \pm 10.87$ & & & No & 231 & $73.74 \pm 12.04$ & & \\
\hline
\end{tabular}

Still smoking $\quad 1 \quad 71.79 \pm 0.00$

\begin{tabular}{|c|c|c|c|c|c|c|c|c|c|}
\hline Drink & & & 2.542 & 0.081 & Emesia & & & 0.948 & 0.344 \\
\hline No drinking & 210 & $73.30 \pm 12.51$ & & & Yes & 4 & $67.47 \pm 17.00$ & & \\
\hline $\begin{array}{l}\text { Used to drink } \\
\text { and q uit } \\
\text { drinking. }\end{array}$ & 26 & $75.15 \pm 9.47$ & & & No & 236 & $73.38 \pm 12.31$ & & \\
\hline Still drinking & 4 & $60.26 \pm 17.30$ & & & & & & & \\
\hline Self-managemen & efficac & & 15.123 & 0.000 & Pain & & & 1.178 & 0.24 \\
\hline High group & 67 & $79.32 \pm 12.79$ & & & Yes & 31 & $70.84 \pm 12.83$ & & \\
\hline Medium group & 113 & $73.29 \pm 12.36$ & & & No & 209 & $73.65 \pm 12.30$ & & \\
\hline Low group & 60 & $67.87 \pm 9.31$ & & & Insomnia & & & 2.66 & 0.008 \\
\hline Current menstrua & status & & 0.873 & 0.419 & Yes & 35 & $68.21 \pm 12.31$ & & \\
\hline Regular & 14 & $77.38 \pm 12.10$ & & & No & 205 & $74.15 \pm 12.21$ & & \\
\hline $\begin{array}{l}\text { Not yet } \\
\text { menopause, but } \\
\text { beginning }\end{array}$ & 59 & $73.51 \pm 11.64$ & & & Others & & & 0.071 & 0.944 \\
\hline Postmenopausal & 167 & $72.86 \pm 12.66$ & & & Yes & 10 & $73.01 \pm 12.50$ & & \\
\hline Postoperative tim & Imonth & & 1.795 & 0.115 & No & 230 & $73.30 \pm 12.40$ & & \\
\hline 1区12 & 76 & $71.30 \pm 11.84$ & & & Recurrenc & or tra & sfer & 2.035 & 0.043 \\
\hline $13 \varangle 24$ & 63 & $75.69 \pm 10.94$ & & & Yes & 9 & $65.10 \pm 16.61$ & & \\
\hline $25 \bowtie 36$ & 42 & $75.70 \pm 13.71$ & & & No & 231 & $73.60 \pm 12.12$ & & \\
\hline $37 \bigotimes 48$ & 30 & $73.53 \pm 11.49$ & & & & & & & \\
\hline
\end{tabular}




\begin{tabular}{lll}
$49 \llbracket 60$ & 20 & $70.19 \pm 12.54$ \\
\hline$\varangle 60$ & 9 & $68.02 \pm 18.78$
\end{tabular}

\section{Multivariate analysis of quality of life of breast cancer patients treated with endocrine therapy}

QOL as a dependent variable, the single factor meaningful variables of age, BMI, marital status, family income, the number of somatic symptoms and types, fatigue, nausea, insomnia, whether metastasis and recurrence selfmanagement effectiveness as independent variables, multiple stepwise regression analysis, the results showed that there were four significant variables included in the regression equation, namely, self-management efficacy, number of physical symptoms, monthly family income, and recurrence and metastasis, which jointly predicted $46.2 \%$ of the variance in quality of life, in which self-management efficacy alone explained $33.6 \%$ of the variance (Table 5).

\section{Regression equation:}

$\mathrm{Y}_{\mathrm{QOL}}^{\prime}=5.445 \mathrm{X}_{\text {Self-management efficacy }}-3.337 \mathrm{X}_{\text {number of physical symptoms }}+2.144 \mathrm{X}_{\text {monthly family income }}-8.660 \mathrm{X}$ recurrence and metastasis +61.255

Table 5 Multiple stepwise regression analysis of influencing factors of QOL $(n=240)$

\begin{tabular}{|c|c|c|c|c|c|}
\hline Item & 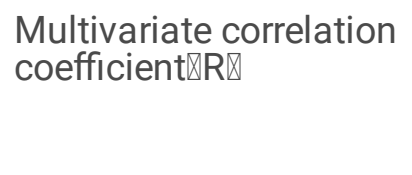 & $\begin{array}{l}\text { Determinant } \\
\text { coefficient } \ R^{2} \square\end{array}$ & $\begin{array}{l}\text { Partial regression } \\
\text { coefficient } \\
\otimes \beta \square\end{array}$ & $t$ & $p$ \\
\hline Constant term & & & 61.255 & 24.055 & 0.000 \\
\hline $\begin{array}{l}\text { Self-management } \\
\text { efficiency }\end{array}$ & 0.336 & 0.113 & 5.445 & 5.516 & 0.000 \\
\hline $\begin{array}{l}\text { Number of physical } \\
\text { symptoms }\end{array}$ & 0.032 & 0.055 & -3.337 & -4.199 & 0.000 \\
\hline $\begin{array}{l}\text { Monthly family } \\
\text { income }\end{array}$ & 0.074 & 0.024 & 2.144 & 2.705 & 0.007 \\
\hline $\begin{array}{l}\text { Recurrence or } \\
\text { metastasis }\end{array}$ & 0.020 & 0.015 & -8.660 & -2.288 & 0.023 \\
\hline
\end{tabular}

\section{Discussion}

\section{Status quo of self-management efficacy in patients with endocrine therapy of breast cancer}

The total score of the questionnaire on self-management efficacy of endocrine therapy for breast cancer patients was 165.00 points. In this study, the average score of the self-management efficacy of breast cancer endocrine therapy patients was 125.21 points, which was at a medium level and consistent with previous research results [1819]. Studies have shown that the course of disease will affect the level of self-management efficacy of patients, and the level of self-management efficacy of patients will decrease with the passage of time [20]. Therefore, in this study, patients were divided into 1 year, 2 years, 3 years, 4 years, 5 years and more than 5 years according to the length of endocrine therapy for comparison. However, the results showed that there was no significant difference in the scores of self-management efficacy among patients with different periods of endocrine therapy $(p>0.05)$, which may be due to the good physiological and psychological status of most patients with endocrine therapy in this study, and the adequate family and social support system, which made patients confident to adhere to long-term treatment. 


\section{QOL status quo in patients with endocrine therapy of breast cancer of breast cancer}

The average score of QOL of breast cancer patients treated with endocrine therapy was 73.29, which was at a medium level, consistent with the results of Montagnese et al. [21]. Among all the dimensions, the score of psychological function was the lowest, which may be related to breast cancer patients' inferiority about the change of their own image, the worry about the disease and treatment, and the symptom confusion caused by endocrine therapy.

\section{Correlation between self-management efficacy and QOL in patients with endocrine therapy of breast cancer}

The results of this study showed that there was a positive correlation between self-management efficacy and quality of life $(p<0.01)$, which indicated that the higher the level of self-management efficacy, the better the QOL, which was consistent with previous research results $[18,22-24]$. At the same time, the results of this study showed that the selfmanagement efficacy of patients with breast cancer endocrine therapy was positively correlated with the physical function dimension, physiological function dimension, social function dimension and breast cancer-specific module of QOL $(p<0.01)$, which indicated that improving the self-management efficacy of patients with breast cancer endocrine therapy can improve their physical, physiological and social function and other aspects of life quality. However, in the results of this study, the common symptoms and side effects of self-management efficacy and QOL were not related, which may be due to the difference between the symptoms and side effects contained in the dimension of QOL scale for breast cancer patients and the physical symptoms and side effects experienced by breast cancer patients during endocrine therapy. In addition, the life/emotion dimension, disease coping dimension, social/family dimension and compliance behavior dimension of self-management efficacy were positively correlated with the quality of life $(p<0.01)$, which indicated that when the self-management efficacy level of daily life and emotions is high, positive emotions can be improved while negative emotions can be reduced to broaden the patient's thinking-behavior system and establish an effective coping mode [23, 25], so as to better cope with diseases and achieve social and family functions. In addition, breast cancer patients with a strong sense of self-efficacy can face the stress caused by the disease with a more optimistic and positive attitude, actively seek the help of medical staff and the support of family and society, build up confidence in fighting the disease, actively participate in the management of the disease, and reduce the influence of disease and treatment on the overall health and QOL [2627].

\section{Analysis of influencing factors of QOL in patients with endocrine therapy of breast cancer}

In this study, the factors influencing the QOL of patients with breast cancer undergoing endocrine therapy were analyzed by one-way ANOVA, and it found that age, BMI, marital status, monthly family income, the number and types of physical symptoms, fatigue, nausea, insomnia, recurrence and metastasis and self-management efficacy had significant influence on the QOL $(p<0.05)$.

Because single factor analysis can't control the influence of confounding factors and the information obtained from comprehensive analysis, the comparability of data is slightly poor and the results are relatively limited. Multi-factor analysis has the characteristics of high efficiency and reliable results, and through comprehensive analysis, it can eliminate atypical and unrepresentative factors and find out the real factors. Therefore, in order to eliminate the possible interaction among various factors, this study took the QOL as the dependent variable, and meaningful variables in single factor analysis as the independent variable, and carried out multiple stepwise regression analysis to screen the most important influencing factors of the QOL of breast cancer patients undergoing endocrine therapy. 
The results showed that the variables entered the regression equation were self-management efficacy, number of physical symptoms, monthly family income, recurrence or metastasis, which jointly predicted the variation of $46.2 \%$ of the QOL of patients with breast cancer undergoing endocrine therapy. It was suggested that the higher the selfmanagement efficacy level of breast cancer endocrine therapy patients, the better the QOL, which was consistent with the previous research results $[18,22-24,28]$. Bandura[29] thought self-efficacy can affect human health by influencing individual's physical and mental regulation system, such as influencing individual's health habits and directly controlling individual's physiological aging. Therefore, self-efficacy can make breast cancer patients reach the physiological, psychological and social health state by regulating the physical and mental system, thus affecting their quality of life. Patients with high self-efficacy, when faced with difficulties and challenges, often don't fear difficulties, often can make their ability to solve problems outstandingly, show better self-management ability, better grasp the relevant knowledge and skills of self-management healthy behaviors, adhere to daily life and emotional management, adhere to self-condition monitoring, adhere to correct self-management behaviors and improve their quality of life; on the contrary, patients with low self-efficacy often question their abilities and tend to adopt negative or evasive coping styles when facing diseases, which easily leads to the generation of bad emotions such as anxiety, depression, pessimism, disappointment, etc., which is not conducive to the formation of correct self-management behaviors and new healthy behaviors, and leads to the decline of quality of life [22, 26, 28, 30-31]. Secondly, the number of physical symptoms, family monthly income and whether recurrence or metastasis also enter the regression equation. The fewer physical symptoms, the higher monthly income of family, and the better QOL if there is no recurrence or metastasis [26, 32-35].

To sum up, the self-management efficacy of breast cancer patients undergoing endocrine therapy is the most important factor affecting their QOL. The higher the self-management efficacy level of breast cancer patients, the better their QOL.

\section{Conclusion}

Self-management efficacy and QOL of patients with breast cancer undergoing endocrine therapy are in the middle level, and self-management efficacy is positively correlated with QOL. Self-management efficacy of breast cancer patients undergoing endocrine therapy is an important factor affecting their QOL. In nursing work, we should pay attention to the status of self-management efficacy of breast cancer patients, and take corresponding nursing measures to help patients improve their self-management efficacy, self-management behavior and treatment compliance, so as to prolong their lives and improve their QOL.

\section{Declarations}

Funding: Liaoning Province Science and Technology Planning project (No.2015225023)

Conflicts of interest: The researchers declare no conflict of interests.

Availability of data and material: Data and material are available upon request.

Code availability: The IBM SPSS statistics 20.0 was utilized to analyze the data.

Authors' contributions: All authors contributed to the study conception and design. Material preparation, data collection, analysis were performed and the first draft of the manuscript was written by Hongjie Yi. All authors commented on previous versions of the manuscript. All authors read and approved the final manuscript.

Page $11 / 14$ 
Ethics approval: The study project was approved by The First Affiliated Hospital of China Medical University Medical Science Research Ethics Committee (No. [2016] 2016-5-2)

Consent to participate: Informed consent was sought and gained from all study participants.

Consent for publication: All the authors agreed to publish this article.

\section{References}

1. Bray F, Ferlay J, Soerjomataram I, et al. Global cancer statistics 2018: GLOBOCAN estimates of incidence and mortality worldwide for 36 cancers in 185 countries [J]. CA Cancer J Clin, 2018, 68(6): 394-424. https://doi.org/10.3322/caac.21492

2. Fitzmaurice C, Abate D, Abbasi N, et al. Global, Regional, and National Cancer Incidence, Mortality, Years of Life Lost, Years Lived With Disability, and Disability-Adjusted Life-Years for 29 Cancer Groups, 1990 to 2017: A Systematic Analysis for the Global Burden of Disease Study [J]. JAMA oncology, 2019, 5(12): 17491768.https://doi.org/10.1001/jamaoncol.2019.2996

3. WHO. Cancer fact sheets [EB/OL]. (2020-12). [2021-11-08]. https://gco.iarc.fr/today/data/factsheets/cancers/20-Breast-fact-sheet.pdf

4. Li T, Mello-Thoms C, Brennan P C. Descriptive epidemiology of breast cancer in China: incidence, mortality, survival and prevalence [J]. Breast Cancer Res Treat, 2016, 159(3): 395-406. https://doi.org/10.1007/s10549016-3947-0

5. Ramchand S K, Cheung Y M, Yeo B, et al. The effects of adjuvant endocrine therapy on bone health in women with breast cancer [J]. The Journal of endocrinology, 2019, 241(3): R111-r124. https://doi.org/10.1530/JOE-190077

6. Hanker A B, Sudhan D R, Arteaga C L. Overcoming Endocrine Resistance in Breast Cancer [J]. Cancer cell, 2020, 37(4): 496-513. https://doi.org/10.1016/j.ccell.2020.03.009

7. Li P, Wu W, Qian L, et al. Progress in endocrine therapy for early breast cancer [J]. Zhong nan da xue xue bao Yi xue ban = Journal of Central South University Medical sciences, 2019, 44(11): 1268-1274. https://doi.org/10.11817/j.issn.1672-7347.2019.190289

8. Sebaoun P, Frederic M, Weryha G, et al. Tolerance of Tamoxifen as an adjuvant therapy and long-term follow up of 55 premenopausal breast cancer women, cared for at the Institut de cancérologie de Lorraine, treated with Tamoxifen [J]. Bulletin du cancer, 2019, 106(12s1): S75-S100. https://doi.org/10.1016/S0007-4551(20)30050-3

9. Condorelli R, Vaz-Luis I. Managing side effects in adjuvant endocrine therapy for breast cancer [J]. Expert Rev Anticancer Ther, 2018, 18(11): 1101-1112. https://doi.org/10.1080/14737140.2018.1520096

10. Kuba S, Ishida M, Nakamura Y, et al. Persistence and discontinuation of adjuvant endocrine therapy in women with breast cancer [J]. Breast cancer (Tokyo, Japan), 2016, 23(1): 128-133. https://doi.org/10.1007/s12282-0140540-4

11. Toivonen K I, Williamson T M, Carlson L E, et al. Potentially Modifiable Factors Associated with Adherence to Adjuvant Endocrine Therapy among Breast Cancer Survivors: A Systematic Review [J]. Cancers, 2020, 13(1): 107. https://doi.org/10.3390/cancers13010107

12. Choo S B, Saifulbahri A, Zullkifli S N, et al. Adjuvant endocrine therapy side-effects among postmenopausal breast cancer patients in Malaysia [J]. Climacteric : the journal of the International Menopause Society, 2019, 22(2): 175-181.https://doi.org/10.1080/13697137.2018.1540563

Page 12/14 
13. Wu F, Howell D, Fang Q, et al. Trajectory Patterns and Factors Influencing Self-management Behaviors in Chinese Patients With Breast Cancer [J]. Cancer Nurs, 2020, 43(2): E105-

E112.https://doi.org/10.1097/NCC.0000000000000681

14. Yi H J, Wang A P, Pan K N, et al. Development and reliability and validity test of self-management efficacy questionnaire for breast cancer patients receiving endocrine therapy [J]. Chinese Nursing Research, 2018, 32(01): 89-94. https://doi.org/10.3969/j.issn.1009-6493.2018.01.023

15. Yang Z, Tang X L, Wan C H, et al. Development of the system of quality of life instruments for patients with breast cancer (QLICP-BR) [J]. Ai zheng = Aizheng = Chinese journal of cancer, 2007, 26(10): 1122-1126.

16. Wan C, Yang Z, Tang X, et al. Development and validation of the system of quality of life instruments for cancer patients: breast cancer (QLICP-BR) [J]. Supportive care in cancer : official journal of the Multinational Association of Supportive Care in Cancer, 2009, 17(4): 359-366. https://doi.org/10.1007/s00520-008-0478-1

17. Ye M. Evaluation of QLICP-BR questionnaire in breast cancer patients undergoing chemotherapy [D]; Anhui Medical University, 2009.

18. Haas B K. Fatigue, self-efficacy, physical activity, and quality of life in women with breast cancer [J]. Cancer Nurs, 2011, 34(4): 322-334. https://doi.org/10.1097/NCC.0b013e3181f9a300

19. Awick E A, Phillips S M, Lloyd G R, et al. Physical activity, self-efficacy and self-esteem in breast cancer survivors: a panel model [J]. Psychooncology, 2017, 26(10): 1625-1631.https://doi.org/10.1002/pon.4180

20. Jang M, Kim J. A structural model for stress, coping, and psychosocial adjustment: A multi-group analysis by stages of survivorship in Korean women with breast cancer [J]. Eur J Oncol Nurs, 2018, 33(41-48).

https://doi.org/10.1016/j.ejon.2018.01.004

21. Montagnese C, Porciello G, Vitale S, et al. Quality of Life in Women Diagnosed with Breast Cancer after a 12 Month Treatment of Lifestyle Modifications [J]. Nutrients, 2020, 13(1): 136.

https://doi.org/10.3390/nu13010136

22. Shelby R A, Edmond S N, Wren A A, et al. Self-efficacy for coping with symptoms moderates the relationship between physical symptoms and well-being in breast cancer survivors taking adjuvant endocrine therapy [J]. Supportive care in cancer : official journal of the Multinational Association of Supportive Care in Cancer, 2014, 22(10): 2851-2859.https://doi.org/10.1007/s00520-014-2269-1

23. Yeung N C, Lu Q. Affect as a mediator between self-efficacy and quality of life among Chinese cancer survivors in China [J]. European journal of cancer care, 2014, 23(1): 149-155.https://doi.org/10.1111/ecc.12123

24. Yeung N C, Lu Q, Lin W. Specificity may count: not every aspect of coping self-efficacy is beneficial to quality of life among Chinese cancer survivors in China [J]. Int J Behav Med, 2014, 21(4): 629-637.

https://doi.org/10.1007/s12529-014-9394-6

25. Fatiregun O A, Olagunju A T, Erinfolami A R, et al. Relationship between anxiety disorders and domains of health related quality of life among Nigerians with breast cancer [J]. Breast (Edinburgh, Scotland), 2017, 31(150-156). https://doi.org/10.1016/j.breast.2016.11.010

26. Akin S, Kas Guner C. Investigation of the relationship among fatigue, self-efficacy and quality of life during chemotherapy in patients with breast, lung or gastrointestinal cancer [J]. European journal of cancer care, 2019, 28(1): e12898.https://doi.org/10.1111/ecc.12898

27. Teo I, Fingeret M C, Liu J, et al. Coping and quality of life of patients following microsurgical treatment for breast cancer-related lymphedema [J]. J Health Psychol, 2016, 21(12): 2983-

2993.https://doi.org/10.1177/1359105315589801

Page 13/14 
28. Gaston-Johansson F, Fall-Dickson J M, Nanda J P, et al. Long-term effect of the self-management comprehensive coping strategy program on quality of life in patients with breast cancer treated with high-dose chemotherapy [J]. Psychooncology, 2013, 22(3): 530-539.https://doi.org/10.1002/pon.3031

29. Bandura A. Self-efficacy: toward a unifying theory of behavioral change [J]. Psychological review, 1977, 84(2): 191-215. https://doi.org/10.1037//0033-295x.84.2.191

30. Chirico A, Serpentini S, Merluzzi T, et al. Self-efficacy for Coping Moderates the Effects of Distress on Quality of Life in Palliative Cancer Care [J]. Anticancer research, 2017, 37(4): 16091615.https://doi.org/10.21873/anticanres.11491

31. Adams R N, Mosher C E, Cohee A A, et al. Avoidant coping and self-efficacy mediate relationships between perceived social constraints and symptoms among long-term breast cancer survivors [J]. Psychooncology, 2017, 26(7): 982-990. https://doi.org/10.1002/pon.4119

32. Tran T H, Trinh N L, Hoang Y, et al. Health-Related Quality of Life Among Vietnamese Breast Cancer Women [J]. Cancer Control, 2019, 26(1): 1073274819862787.https://doi.org/10.1177/1073274819862787

33. Hauth F, De-Colle C, Weidner N, et al. Quality of life and fatigue before and after radiotherapy in breast cancer patients [J]. Strahlentherapie und Onkologie : Organ der Deutschen Rontgengesellschaft [et al], 2021, 197(4): 281-287. https://doi.org/10.1007/s00066-020-01700-1

34. Abu-Saad Huijer $\mathrm{H}$, Abboud S. Health-related quality of life among breast cancer patients in Lebanon [J]. Eur J Oncol Nurs, 2012, 16(5): 491-497. https://doi.org/10.1016/j.ejon.2011.11.003

35. El Haidari R, Abbas L A, Nerich V, et al. Factors Associated with Health-Related Quality of Life in Women with Breast Cancer in the Middle East: A Systematic Review [J]. Cancers, 2020, 12(3): 696.

https://doi.org/10.3390/cancers12030696 